\title{
Changes in community knowledge and attitudes related to female genital fistula following the implementation of a multi-component intervention in Nigeria and Uganda
}

\author{
Karen Kirk ${ }^{1}$ (D, Pooja Sripad ${ }^{2}$, Charity Ndwiga ${ }^{3}$, Emmanuel Nwala ${ }^{4}$, George Odwe ${ }^{3}$, Charlotte Warren $^{2}$ \\ ${ }^{1}$ Reproductive Health Program, Population Council, New York, ${ }^{2}$ Reproductive Health Program, Population Council, Washington, DC, 3 Reproductive \\ Health Program, Population Council, Kenya, ${ }^{4}$ Reproductive Health Program, Population Council, Nigeria \\ Keywords: uganda, nigeria, stigma, attitudes, female genital fistula
}

https://doi.org/10.29392/001c.22238

Journal of Global Health Reports

Vol. 5, 2021

\section{Background}

Despite well-documented individual-level barriers to fistula care access including limited awareness, psychosocial deterrents, and contextual factors, less is known about how these factors manifest and operate at community level. Social normative community perspectives - their knowledge, attitudes and actions in relation to women living with fistula - can offer insight into this mechanism. Our study describes changes in fistula knowledge and attitudes toward those living with fistula among community members in Nigeria and Uganda following implementation of a multi-component intervention addressing treatment barriers.

\section{Methods}

This study adopts a pre-post qualitative design with a comparison site and draws on focus group discussions with female and male community members from three sites in Nigeria and Uganda. Transcripts were analyzed for passages presenting community knowledge and attitudes related to fistula and perceptions of women living with fistula. Summary memos were developed and used to compare viewpoints across study sites and time points and between men and women.

\section{Results \\ Community members demonstrated basic knowledge of symptoms of fistula and mixed understanding of its causes; prolonged obstructed labor and iatrogenic causes were most known. Myths and misconceptions around fistula causes commonly relate to incorrect biomedical understanding, witchcraft, and promiscuity. To varying degrees, fistula cause knowledge increased, and misinformation decreased among endline intervention groups with less observed change in endline comparison groups. Awareness that fistula can be surgically repaired free of charge at fistula centers varied across study regions, with higher awareness among individuals who personally knew someone who experienced repair at a center. Although community members at baseline and endline perceive shame and stigma as affecting women living with fistula, community attitudes toward these women show an increase in empathy at endline in intervention areas.}

\section{Conclusions}

Community empathy and willingness to help women living with fistula, coupled with reduction in misinformation regarding fistula, its cause and how to access treatment, is an incremental outcome associated with the implementation of a multi-component intervention to address treatment barriers. However, findings reveal that social and behavioral change happens slowly and that further programmatic research on society-targeted approaches emphasizing comprehensive community understanding of fistula and stigma reduction is needed.

Misconceptions and poor awareness about the causes and treatments for female genital fistula (hereafter referred to as fistula) can impede women from accessing repair services. Every year in sub-Saharan Africa, thousands of women develop fistula, a preventable and treatable condition that results in uncontrollable leakage of urine and/ or feces, and is often caused by obstructed labor without timely or adequate management. ${ }^{1}$ The most commonly-rec- 
Table 1. Number of total Focus Group Discussions conducted with community members

\begin{tabular}{|c|c|c|c|c|c|c|}
\hline & \multicolumn{2}{|l|}{ Baseline* } & \multicolumn{2}{|c|}{ Comparison } & \multicolumn{2}{|c|}{ Intervention } \\
\hline & Women & Men & Women & Men & Women & Men \\
\hline Uganda & 4 & 4 & 2 & 2 & 2 & 2 \\
\hline Ebonyi & 1 & 1 & 2 & 2 & 2 & 2 \\
\hline Katsina & 2 & 2 & 2 & 2 & 2 & 2 \\
\hline
\end{tabular}

*Baseline focus groups cover both comparison and intervention sites.

ognized causes of female genital fistula include prolonged or obstructed labor $(\mathrm{P} / \mathrm{OL})$, iatrogenic or medical error, and sexual violence or trauma. ${ }^{2,3}$ While there are well-documented factors related to individual awareness and psychological barriers to accessing treatment, ${ }^{4}$ there is limited research about how these factors manifest and operate at the community level. Studies exploring community-level knowledge and awareness in Burkina Faso, Malawi, Tanzania and Uganda suggest relevance and potential influence of shared attitudes and norms ${ }^{5-8}$ Society plays a critical role in facilitating care seeking and shaping community attitudes about women living with fistula, subsequently affecting prevailing psychosocial barriers to care. ${ }^{9-11}$

The health and social consequences of fistula affecting an individual's quality of life and her psychological state can be understood by exploring the scope and influence of community awareness of and attitudes on fistula, care options, and the ways communities relate to women living with fistula. Studies rarely move beyond individual-level self-reported stigmatization and related unique consequences for women living with fistula ${ }^{12-14}$ to explore the inextricably linked perspectives of their immediate families and surrounding communities - the social context that underlies and influences the lived experiences of the stigmatized. Few studies examining community-level perspectives of social consequences emphasize the dynamics of social restriction or isolation, particularly the exclusion of women living with fistula from normal community activities or gatherings due to their condition. ${ }^{15-17}$ Social normative perspectives are best assessed qualitatively, through focus group discussions (FGDs) to understand social issues and conventions ${ }^{18}$; though only very few studies, such as one in Malawi, have used this methodology with community members to elicit social norms and perceptions of fistula. ${ }^{7}$

There is a need to further explore social normative perspectives of communities in their knowledge, attitudes and actions in relation to women living with fistula, on the one hand, and evaluate whether these can shift in response to programmatic intervention, on the other.

In response to this need, our study - which is nested within Fistula Care Plus (FC+)'s research-to-action collaboration supported by USAID and implemented by EngenderHealth with research partner Population Council (2015-2021) - implemented a multi-component social and behavior change (SBC) intervention to overcome barriers to fistula care. The intervention employs several strategies, including increasing community awareness through use of mass media messaging about fistula symptoms, treatment availability, and referral mechanisms in parts of Nigeria and
Uganda. ${ }^{19,20}$ The purpose of our study is to describe changes in fistula knowledge and attitudes toward those living with fistula among community members in Nigeria and Uganda following intervention implementation.

\section{METHODS}

\section{STUDY DESIGN AND SETTING}

This study adopts a pre-post qualitative design with a comparison site and draws on 38 qualitative FGDs made up of 6-10 male or female community members in each group from three sites in Nigeria and Uganda. Data were collected prior to and following the intervention in comparison and intervention sites (Table 1). Baseline data were collected between June and December 2015 in Ebonyi State, Nigeria and Central Uganda and between June 2016 and March 2017 in Katsina State, Nigeria and Central Uganda. Endline data (intervention and comparison) were collected in all three sites between July and October 2018. Given the similarities in content within each study site prior to intervention implementation, this study's baseline findings include community attitudes from comparison and intervention areas.

The three study sites reflect geographic and cultural differences representative of Southeastern and Northern Nigeria (e.g., Ebonyi and Katsina States) and Central 1 sub-Region in Uganda (hereafter referred to as Central Uganda); they were also selected based on the capacity of fistula repair centers and discussions with key partners and donors. The intervention areas (Ikwo, Ebonyi State, Katsina, Katsina State, and Kalungu, Central Uganda) and comparison areas (Izzi, Ebonyi State, Batsari, Katsina State, and Masaka, Central Uganda) were selected based on similarities in fistula burden and potential structural access to advanced fistula care. Each study site, for example had accredited hospitals and or referral systems that provide comprehensive fistula diagnosis, surgical and follow up care and were supported as part of the FC+ interventions.

- The National Fistula Center at Abakaliki in Ebonyi, Nigeria

- The National Fistula Center at Babbar Ruga in Katsina, Nigeria

- The Fistula Center at Kitovo Mission Hospital in Masaka District, Central Uganda

\section{DATA COLLECTION}

Male and female community members of reproductive age (15-49 years) were identified by requesting volunteers 
through existing community channels to participate in an FGD. Per local policy, young women 15-17 years considered emancipated minors if married or caring for a child, participated in this study. FGD participants were reimbursed for transportation costs to the venue up to approximately US\$6 (2,000 NGN or 20,000 UGX).

FGDs were led by research assistants (RAs) trained on research ethics, who held the FGDs in community-settings where participants felt open to answer the full range of questions, which include sensitive topics. The RAs were also trained to listen and observe without displaying opinions or judgement. We conducted at least two FGDs with between 6 and 10 participants for nearly all respondent categories; this is in line with common guidelines for focus group research and was recently confirmed as providing a "comprehensive understanding of issues" in a recent study assessing sample sizes in focus group research. ${ }^{21}$

\section{DATA ANALYSIS}

FGDs were audio-recorded, transcribed, and translated into English (from Hausa, Igbo, and Luganda, as necessary). After reading select transcripts, a preliminary coding of the data was carried out by the research teams in Nigeria, Uganda, and US in phases through an inductively derived codebook that was applied first to baseline data and later modified and applied to endline intervention data separately in NVivo 12 (QSR International (Americas), Burlington, MA, USA). All FGD transcripts were later integrated into a combined NVivo 12 Project, re-read, and coded for passages presenting community knowledge and attitudes related to fistula and perceptions of women living with fistula. Summary memos were developed alongside these codes allowing researchers to compare and contrast viewpoints across study sites and time points and between men and women. These passages and memos were further analyzed and summarized into tables that presented correct information and misinformation as well as common themes among community member attitudes and perceptions by site, time point, and gender. This analysis conveys an overall sense of whether each respondent type expressed certain knowledge or attitudes related to fistula. This assessment, presented in Tables $\underline{2}, \underline{3}$, and $\underline{4}$ describes whether or not a particular theme readily emerged from the data.

\section{INTERVENTION DESCRIPTION}

The intervention was created through the research-to-action collaboration process and aimed to reduce awareness, financial, and transportation barriers that impede women's access to fistula treatment. ${ }^{19}$ This multi-component SBC intervention applied a screening algorithm and disseminated fistula-related messaging through three communications channels (mass media and Interactive Voice Recognition (IVR) hotline, community outreach agents, and primary health center (PHC) providers); and offered a transportation voucher to improve access to fistula repair centers. Messaging promoting the IVR hotline included radio spots, billboards in community settings, as well as posters in PHCs (Figure 1). This model was designed to facilitate access to the hospital for fistula diagnosis and repair for

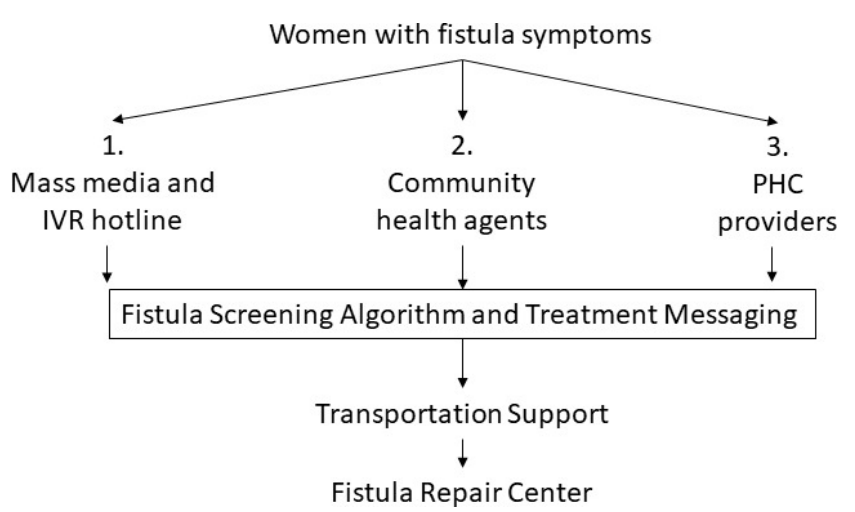

Figure 1. SBC intervention model to reduce barriers to fistula treatment.

women living with fistula in the intervention areas. While comparison areas may have been exposed to media messaging, community agents and PHC providers did not receive $\mathrm{FC}+$ training on fistula prevention, screening, diagnosis, and referral care in these locations.

\section{ETHICS APPROVAL}

Ethical approval for this study was granted by the Population Council's institutional review board (Protocols \#694 and \#733) in New York, USA. In Nigeria, ethical approvals were received from the National Health Research Ethics Committee of the Federal Ministry of Health, Kano State Health Research Ethics Committee, and Ebonyi State Research Ethics Committee State Ministry of Health, and in Uganda, from Makerere University College of Health Sciences School of Medicine Research Ethics Committee.

\section{RESULTS}

A total of 337 respondents participated in the FGDs and participants were evenly split between male and female community members. The majority of participants were married with a minority of approximately 10 percent unmarried (single or widowed). Among participants, community attitudes shifted to varying extents with respect to fistula-related knowledge, barriers, care-seeking options, and support for women living with fistula. Communities' understanding of fistula symptoms sustained over the implementation period in both comparison and intervention sites. Awareness of early marriage and pregnancy as indirect causes of fistula were maintained while causes of traumatic fistula were rarely described over time. While ambiguity around some fistula causes persist, there was an overall reduction in misconceptions across all sites at endline, and particularly intervention areas. Increased awareness about care options are reflected in that communities perceive fistula centers as the ideal treatment venues and fewer community members describe traditional medicine as the "best" option at endline. At endline, communities in intervention sites consistently report empathy, compassion, and willingness to help women living with fistula socially and instrumentally in care-seeking. Cross-country, site-spe- 
cific, and gendered nuances are further explored the remaining sections.

\section{KNOWLEDGE OF FISTULA SYMPTOMS AND CAUSES}

\section{WHAT IS FISTULA? COMMUNITY UNDERSTANDING OF FISTULA SYMPTOMS}

Generally, community members in all sites at baseline and endline knew that fistula is associated with childbirth and involves the bladder and urine, but the association with leaking of feces was better known in Central Uganda than in either Katsina or Ebonyi (Table 2). Overall, most respondents describe fistula as being a damaged or "busted" bladder that leads to leaking urine. Men and women in Central Uganda were aware of the 'uncontrollable' aspect of the leaking from fistula in all three groups while Ebonyi and Katsina showed more mixed comprehension of this factor.

\section{AWARENESS OF DIRECT AND INDIRECT CAUSES OF FISTULA}

The three primary direct causes of fistula include P/OL, iatrogenic or medical error, and sexual violence or trauma. Community awareness of these direct causes of fistula varied by site and cause (Table 3).

Although there was some variation in awareness of $\mathrm{P} /$ OL as a main cause of fistula, the overall level of understanding was sustained across respondent groups and time periods. Across all three sites, women generally were more likely to mention prolonged labor as a cause of fistula, however community men in Central Uganda and Katsina showed some awareness of prolonged labor causing fistula. P/OL was not explicitly described by any of the endline intervention women in Uganda despite women's groups showing some knowledge of this in the baseline and endline comparison groups.

"It depends on the time the woman takes when she is in labor, [...] when they take long, the baby keeps on pressing the bladder or the large intestine and they end up getting damaged and [...] leaking the urine and feces." - Kalungu, Central Uganda, Baseline FGD, Community Women.

"Some of the challenges women face is that people don't assist her to the hospital on time during labor, once it gets prolonged it leads to fistula." - Katsina, Nigeria, Endline Intervention FGD, Community Men.

Iatrogenic causes were cited by baseline women in all sites and men in Central Uganda, who understood that health provider interventions could inadvertently lead to a woman developing fistula. The main examples include: cesarean sections, episiotomies, and dilation and curettage (a procedure to ensure all biproducts of pregnancy have been removed from the uterus; often used following incomplete miscarriage or for abortion).

None of the baseline or endline comparison groups correctly identified sexual violence or rape as among the causes of traumatic fistula. Notably, only one man from endline intervention groups in Ebonyi correctly described that violent sex or rape can cause fistula.

In addition to direct causes, there are several situations or conditions that could be considered indirect causes of fistula. The three main indirect causes that emerged from the FGDs were early marriage/pregnancy, late or poor-quality maternal health care, and improperly managed deliveries by traditional birth attendants (TBAs).

Baseline awareness of the role of early marriage and pregnancy in young women elevating the risk of fistula was consistently high in groups of community men and women in Central Uganda and Katsina (Table 3). These same respondent groups, plus the community women in Ebonyi in the endline comparison sites expressed similar awareness related to early marriage and fistula. The endline intervention data showed that this knowledge was mostly sustained following implementation. Despite endline intervention groups of women not explicitly mentioning early marriage as a potential cause, they did mention that young girls are susceptible.

\section{"R9: When these girls get married, most times early, you see that it is easy for them to contract Fistula. [...] R5: I know someone more like a daughter to me who was given out for marriage at an early age, once it came for her to give birth, she had complications, and these have resulted in Fistula." - Katsina, Nigeria, Endline Intervention FGD, Community Men.}

Mismanagement of delivery by TBAs was mentioned as a cause of fistula in nearly all of the baseline sites and the endline comparison sites; this issue was not described in the endline intervention groups. The indirect cause of delayed or poor-quality care was mentioned by baseline men in all sites, however only endline comparison men in Central Uganda mentioned this. This topic reemerged among endline intervention women in Ebonyi and Katsina as well as men in Central Uganda and Ebonyi.

\section{MYTHS AND MISCONCEPTIONS RELATED TO CAUSES OF FISTULA}

Myths and misconceptions related to causes of fistula most commonly related to incorrect biomedical understanding, witchcraft, and promiscuity. Other inaccurate perceptions about the causes of fistula included: bumpy roads, poor hygiene, and religion (the will of God), among others. Misinformation was common among all respondent groups (Table 4).

Misunderstanding of the biomedical causes of fistula included a wide variety of factors. Although use of forceps during delivery was strongly thought to be a direct cause of fistula among Central Uganda baseline women and men and endline comparison men that fistula, this factor is not a significant contributor to fistula cases, ${ }^{22}$ and was not mentioned by the endline intervention groups. One incorrect iatrogenic cause commonly reported among women (and not men) across all three study sites and persisting endline intervention was the belief that the birth attendant (midwife, doctor or TBA) caused damage with their fingernails during vaginal examinations. Other medical misconceptions that linked fistula to pre-existing conditions include infections, fever, stroke etc., too many pregnancies (especially close together), and holding in urine for an extended time and these varied across respondent groups (Table 4). 
Table 2. Community members' knowledge of Fistula and its symptoms, as explicitly mentioned in qualitative group discussions

\begin{tabular}{|c|c|c|c|c|c|c|c|c|c|c|}
\hline & & \multicolumn{3}{|c|}{ Central Uganda, Uganda } & \multicolumn{3}{|c|}{ Ebonyi, Nigeria } & \multicolumn{3}{|c|}{ Katsina, Nigeria } \\
\hline & & $\begin{array}{c}\text { Pre- } \\
\text { Intervention }\end{array}$ & $\begin{array}{c}\text { Non- } \\
\text { Intervention }\end{array}$ & $\begin{array}{l}\text { Post- } \\
\text { intervention }\end{array}$ & $\begin{array}{c}\text { Pre- } \\
\text { Intervention }\end{array}$ & $\begin{array}{c}\text { Non- } \\
\text { Intervention }\end{array}$ & $\begin{array}{l}\text { Post- } \\
\text { intervention }\end{array}$ & $\begin{array}{c}\text { Pre- } \\
\text { Intervention }\end{array}$ & $\begin{array}{c}\text { Non- } \\
\text { Intervention }\end{array}$ & $\begin{array}{c}\text { Post- } \\
\text { intervention }\end{array}$ \\
\hline \multicolumn{11}{|c|}{ Correct knowledge* } \\
\hline \multirow{2}{*}{$\begin{array}{l}\text { Associated with } \\
\text { childbirth }\end{array}$} & Women & $\sqrt{ }$ & $\sqrt{ }$ & $\sqrt{ }$ & $\sqrt{ }$ & $\sqrt{ }$ & $\sqrt{ }$ & $\sqrt{ }$ & $\sqrt{ }$ & $\sqrt{ }$ \\
\hline & Men & $\sqrt{ }-$ & $\sqrt{ }$ & $\sqrt{ }$ & $\sqrt{ }$ & $x$ & $\sqrt{ }$ & $\sqrt{ }$ & $\sqrt{ }$ & $\sqrt{ }$ \\
\hline \multirow{2}{*}{$\begin{array}{l}\text { Uncontrollable } \\
\text { leaking }\end{array}$} & Women & $\sqrt{ }$ & $\sqrt{ }-$ & $\sqrt{ }$ & $x$ & $\sqrt{ }$ & $\sqrt{ }$ & $x$ & $\sqrt{ }$ & $\sqrt{ }$ \\
\hline & Men & $\sqrt{ }$ & $\sqrt{ }$ & $\sqrt{ }$ & $x$ & $x$ & $\sqrt{ }$ & $\sqrt{ }$ & $\sqrt{ }$ & $\sqrt{ }$ \\
\hline \multirow{2}{*}{ Leaking of urine } & Women & $\sqrt{ }$ & $\sqrt{ }$ & $\sqrt{ }$ & $\sqrt{ }$ & $\sqrt{ }$ & $\sqrt{ }$ & $\sqrt{ }$ & $\sqrt{ }$ & $\sqrt{ }$ \\
\hline & Men & $\sqrt{ }$ & $\sqrt{ }$ & $\sqrt{ }$ & $\sqrt{ }$ & $\sqrt{ }-$ & $\sqrt{ }$ & $\sqrt{ }$ & $\sqrt{ }$ & $\sqrt{ }$ \\
\hline \multirow{2}{*}{ Leaking of feces } & Women & $\sqrt{ }$ & $\sqrt{ }$ & $x$ & $x$ & $x$ & $x$ & $x$ & $x$ & $x$ \\
\hline & Men & $\sqrt{ }$ & $\sqrt{ }$ & $\sqrt{ }$ & $x$ & $x$ & $x$ & $x$ & $x$ & $x$ \\
\hline \multirow{2}{*}{$\begin{array}{l}\text { Damage to the } \\
\text { bladder, urinary } \\
\text { tract, or } \\
\text { intestines/ } \\
\text { colon }\end{array}$} & Women & $\sqrt{ }$ & $x$ & $x$ & $x$ & $\sqrt{ }$ & $\sqrt{ }$ & $x$ & $x$ & $x$ \\
\hline & Men & $\sqrt{ }$ & $x$ & $x$ & $\sqrt{ }$ & $x$ & $\sqrt{ }$ & $x$ & $x$ & $x$ \\
\hline
\end{tabular}

* $\sqrt{ }$ : Topic freely expressed, $\mathrm{X}$ : Topic not freely expressed by respondents, ${ }^{-}$: Some lack of awareness/knowledge in groups' responses 
Table 3. Community comprehension of direct and indirect causes of fistula

\begin{tabular}{|c|c|c|c|c|c|c|c|c|c|c|}
\hline & & \multicolumn{3}{|c|}{ Central-1, Uganda } & \multicolumn{3}{|c|}{ Ebonyi, Nigeria } & \multicolumn{3}{|c|}{ Katsina, Nigeria } \\
\hline & & $\begin{array}{c}\text { Pre- } \\
\text { Intervention }\end{array}$ & $\begin{array}{c}\text { Non- } \\
\text { Intervention }\end{array}$ & $\begin{array}{l}\text { Post- } \\
\text { intervention }\end{array}$ & $\begin{array}{c}\text { Pre- } \\
\text { Intervention }\end{array}$ & $\begin{array}{c}\text { Non- } \\
\text { Intervention }\end{array}$ & $\begin{array}{c}\text { Post- } \\
\text { intervention }\end{array}$ & $\begin{array}{c}\text { Pre- } \\
\text { Intervention }\end{array}$ & $\begin{array}{c}\text { Non- } \\
\text { Intervention }\end{array}$ & $\begin{array}{c}\text { Post- } \\
\text { intervention }\end{array}$ \\
\hline \multicolumn{11}{|c|}{ Direct Causes of Fistula* } \\
\hline \multirow{2}{*}{$\begin{array}{l}\text { Prolonged/ } \\
\text { Obstructed } \\
\text { labor }\end{array}$} & Women & $\sqrt{ }$ & $\sqrt{ }$ & $x$ & $x$ & $\sqrt{ }$ & $\sqrt{ }$ & $\sqrt{ }$ & $\sqrt{ }$ & $\sqrt{ }$ \\
\hline & Men & $\sqrt{ }$ & & $\sqrt{ }$ & $x$ & $x$ & $\mathrm{x}$ & $x$ & $\sqrt{ }$ & $\sqrt{ }$ \\
\hline \multirow{2}{*}{$\begin{array}{l}\text { latrogenic/ } \\
\text { Provider error } \\
\text { (cesarean } \\
\text { section, } \\
\text { abortion, etc.) }\end{array}$} & Women & $\sqrt{ }$ & $\sqrt{ }$ & $\sqrt{ }$ & $\sqrt{ }$ & $\sqrt{ }$ & $x$ & $\sqrt{ }$ & $\mathrm{x}$ & $x$ \\
\hline & Men & $\sqrt{ }$ & $x$ & $\sqrt{ }$ & $x$ & $x$ & $\sqrt{ }$ & $x$ & $\sqrt{ }$ & $\sqrt{ }$ \\
\hline \multirow{2}{*}{$\begin{array}{c}\text { Sexual violence/ } \\
\text { Trauma }\end{array}$} & Women & $x$ & $\sqrt{ }$ & $x$ & $x$ & $x$ & $x$ & $x$ & $x$ & $x$ \\
\hline & Men & $x$ & $x$ & $x$ & $x$ & $x$ & $\sqrt{ }$ & $x$ & $\sqrt{ }$ & $x$ \\
\hline \multicolumn{11}{|c|}{ Indirect Causes of Fistula } \\
\hline \multirow{2}{*}{$\begin{array}{c}\text { Early marriage/ } \\
\text { pregnancy }\end{array}$} & Women & $\sqrt{ }$ & $\sqrt{ }$ & $x$ & $x$ & $x$ & $x$ & $\sqrt{ }$ & $\sqrt{ }$ & $\sqrt{ }$ \\
\hline & Men & $\sqrt{ }$ & $\sqrt{ }$ & $\sqrt{ }$ & $x$ & $x$ & $\sqrt{ }$ & $\sqrt{ }$ & $x$ & $\sqrt{ }$ \\
\hline \multirow{2}{*}{$\begin{array}{l}\text { Mismanagement } \\
\text { of delivery by } \\
\text { TBAs }\end{array}$} & Women & $\sqrt{ }$ & $x$ & $\sqrt{ }$ & $\sqrt{ }$ & $\sqrt{ }$ & $\sqrt{ }$ & $x$ & $x$ & $x$ \\
\hline & Men & $x$ & $\sqrt{ }$ & $\sqrt{ }$ & $\sqrt{ }$ & $\sqrt{ }$ & $x$ & $x$ & $x$ & $x$ \\
\hline \multirow{2}{*}{$\begin{array}{l}\text { Delays in care } \\
\text { seeking/ } \\
\text { Poor care } \\
\text { seeking (ANC } \\
\text { and labor/ } \\
\text { delivery; } \\
\text { inaccessibility of } \\
\text { health centers) }\end{array}$} & Women & $x$ & $x$ & $x$ & $x$ & $x$ & $x$ & $x$ & $\sqrt{ }$ & $\sqrt{ }$ \\
\hline & Men & $\sqrt{ }$ & $\sqrt{ }$ & $\sqrt{ }$ & $\sqrt{ }$ & $x$ & $x$ & $\sqrt{ }$ & $\sqrt{ }$ & $x$ \\
\hline
\end{tabular}

* $\checkmark$ : Topic freely expressed, X: Topic not freely expressed by respondents, ${ }^{-}$: Some lack of awareness/knowledge in groups' responses, TBA - traditional birth attendant 
Table 4. Myths and Misconceptions associated with Fistula

\begin{tabular}{|c|c|c|c|c|c|c|c|c|c|c|}
\hline & & \multicolumn{3}{|c|}{ Central-1, Uganda } & \multicolumn{3}{|c|}{ Ebonyi, Nigeria } & \multicolumn{3}{|c|}{ Katsina, Nigeria } \\
\hline & & $\begin{array}{c}\text { Pre- } \\
\text { Intervention }\end{array}$ & $\begin{array}{c}\text { Non- } \\
\text { Intervention }\end{array}$ & $\begin{array}{c}\text { Post- } \\
\text { intervention }\end{array}$ & $\begin{array}{c}\text { Pre- } \\
\text { Intervention }\end{array}$ & $\begin{array}{c}\text { Non- } \\
\text { Intervention }\end{array}$ & $\begin{array}{c}\text { Post- } \\
\text { intervention }\end{array}$ & $\begin{array}{c}\text { Pre- } \\
\text { Intervention }\end{array}$ & $\begin{array}{c}\text { Non- } \\
\text { Intervention }\end{array}$ & $\begin{array}{c}\text { Post- } \\
\text { intervention }\end{array}$ \\
\hline \multicolumn{11}{|c|}{ Myths and Misconceptions* } \\
\hline \multirow{2}{*}{$\begin{array}{c}\text { Pre-existing } \\
\text { conditions (e.g. } \\
\text { infection, fever, } \\
\text { strokes, } \\
\text { paralysis) }\end{array}$} & Women & $\sqrt{ }$ & $\sqrt{ }$ & $\sqrt{ }$ & $x$ & $x$ & $x$ & $x$ & $x$ & $x$ \\
\hline & Men & $x$ & $\sqrt{ }$ & $\sqrt{ }$ & $\sqrt{ }$ & $\sqrt{ }$ & $\sqrt{ }$ & $x$ & $\sqrt{ }$ & $x$ \\
\hline \multirow{2}{*}{$\begin{array}{l}\text { Holding in urine } \\
\text { for an extended } \\
\text { time }\end{array}$} & Women & $x$ & $\sqrt{ }$ & $\sqrt{ }$ & $x$ & $x$ & $x$ & $x$ & $\sqrt{ }$ & $x$ \\
\hline & Men & $x$ & $x$ & $x$ & $x$ & $x$ & $x$ & $x$ & $x$ & $\sqrt{ }$ \\
\hline \multirow{2}{*}{$\begin{array}{l}\text { Non-violent, } \\
\text { consensual, } \\
\text { sexual } \\
\text { intercourse } \\
\text { and/or } \\
\text { promiscuity* }\end{array}$} & Women & $\sqrt{ }$ & $\sqrt{ }$ & $x$ & $x$ & $\sqrt{ }-$ & $x$ & $x$ & $\sqrt{-}$ & $\sqrt{ }$ \\
\hline & Men & $x$ & $\sqrt{ }$ & $\sqrt{ }-$ & $\sqrt{ }-$ & $\sqrt{ }$ & $x$ & $x$ & $x$ & $\sqrt{ }-$ \\
\hline \multirow{2}{*}{$\begin{array}{l}\text { Use of forceps } \\
\text { during assisted } \\
\text { delivery }\end{array}$} & Women & $\sqrt{ }$ & $\sqrt{ }$ & $x$ & $x$ & $x$ & $x$ & $x$ & $x$ & $x$ \\
\hline & Men & $\sqrt{ }$ & $x$ & $x$ & $x$ & $x$ & $x$ & $x$ & $x$ & $x$ \\
\hline \multirow{2}{*}{$\begin{array}{l}\text { Damage caused } \\
\text { by manual } \\
\text { examination/ } \\
\text { fingernails }\end{array}$} & Women & $\sqrt{ }$ & $\sqrt{ }$ & $\sqrt{ }$ & $x$ & $\sqrt{ }$ & $\sqrt{ }$ & $\sqrt{ }$ & $\sqrt{ }$ & $x$ \\
\hline & Men & $x$ & $x$ & $x$ & $x$ & $\sqrt{ }$ & $\sqrt{ }$ & $x$ & $x$ & $x$ \\
\hline \multirow{2}{*}{$\begin{array}{l}\text { Related to } \\
\text { multiple } \\
\text { pregnancies, } \\
\text { especially close } \\
\text { together }\end{array}$} & Women & $x$ & $x$ & $x$ & $x$ & $\sqrt{ }$ & $\sqrt{ }$ & $\sqrt{ }$ & $\sqrt{ }$ & $\sqrt{ }$ \\
\hline & Men & $x$ & $x$ & $x$ & $x$ & $\sqrt{ }$ & $x$ & $\sqrt{ }$ & $x$ & $\sqrt{ }$ \\
\hline \multirow{2}{*}{$\begin{array}{l}\text { Witchcraft/ } \\
\text { local belief }\end{array}$} & Women & $\sqrt{ }$ & $x$ & $x$ & $\sqrt{ }$ & $x$ & $x$ & $x$ & $x$ & $\sqrt{ }$ \\
\hline & Men & $x$ & $x$ & $x$ & $x$ & $x$ & $\sqrt{ }$ & $\sqrt{ }$ & $x$ & $x$ \\
\hline \multirow{2}{*}{$\begin{array}{l}\text { Sex between } \\
\text { grown men and } \\
\text { girls/young } \\
\text { women }\end{array}$} & Women & $\sqrt{ }$ & $x$ & $\sqrt{ }$ & $x$ & $x$ & $x$ & $x$ & $\sqrt{ }$ & $x$ \\
\hline & Men & $x$ & $x$ & $x$ & $x$ & $x$ & $x$ & $x$ & $x$ & $x$ \\
\hline Big baby & Women & $\sqrt{ }$ & $x$ & $\sqrt{ }$ & $x$ & $x$ & $x$ & $x$ & $x$ & $x$ \\
\hline
\end{tabular}


Changes in community knowledge and attitudes related to female genital fistula following the implementation of a...

\begin{tabular}{|c|c|c|c|c|c|c|c|c|c|c|}
\hline & Men & $x$ & $x$ & $x$ & $x$ & $x$ & $\checkmark$ & $x$ & $x$ & $x$ \\
\hline \multirow{2}{*}{$\begin{array}{l}\text { Miscellaneous } \\
\text { (bumpy roads, } \\
\text { spontaneous, } \\
\text { poor personal } \\
\text { hygiene, } \\
\text { hormones, } \\
\text { falling etc.) }\end{array}$} & Women & $x$ & $\sqrt{ }$ & $x$ & $x$ & $\sqrt{ }$ & $x$ & $\sqrt{ }$ & $\sqrt{ }$ & $x$ \\
\hline & Men & $\checkmark$ & $\checkmark$ & $x$ & $x$ & $\checkmark$ & $x$ & $x$ & $\checkmark$ & $\sqrt{ }$ \\
\hline
\end{tabular}

* $\checkmark$ : Topic freely expressed, $X:$ Topic not freely expressed by respondents, ${ }^{-}:$Some lack of awareness/knowledge in groups' responses 
Cultural misconceptions were not highly prevalent; however, causes like witchcraft or God's will were more prominently and freely offered as causes of fistula in the baseline groups (Central Uganda women, Ebonyi women, and Katsina men) ( ). There was an observed, subtle reduction in unprompted discussions of bewitching as a cause of fistula; the endline intervention groups that mentioned witchcraft did so following probing questions about cultural beliefs.

\begin{abstract}
"Some think its witchcraft. [...] This is a result of ignorance. But if she was sensitized and understands that that is a disease that can be treated in hospital, she would have come early. But because she was not educated, she will think its witchcraft." -Central Uganda, Uganda, Endline Intervention FGD, Community Women.
\end{abstract}

In Central Uganda, baseline groups (men and women) not only described women with fistula seeking herbal treatment, but they posited the use of herbs as potentially causing fistula by "softening the internal system." In Ebonyi, local herbs are described in the context of an old preventative practice in their community. A man from a baseline group described women, "in ages before [...] drinking local herbs prepared by the traditional birth attendant” leading her to "deliver safely, without any complications." When prompted about whether there are any cultural or traditional beliefs related to causes of fistula, the endline comparison women in Ebonyi described that one might think that their fistula was caused by a failure to perform a traditional rite.

Promiscuity or sexual appetite as causing fistula was commonly mentioned in male groups ( $\underline{\text { Table } 4})$. These perceived incorrect causes include: adultery, heightened female sexual appetite, unmarried women having affairs, women having sex with many men, having sex with a man who has a large penis and young girls having sex (not related to early marriage). Although there was rarely mention of these causes in the baseline groups, the endline comparison groups in all three sites mentioned misconceptions about voluntary sexual behavior and only endline intervention male groups mentioned such causes.

\footnotetext{
"Many women, both widows and others, in our villages here... some women are not married to one man, the woman may be sleeping around, when it gets out of hand it can cause problem, this man will go, another man will go again, it can cause problem, something will spoil... her [bladder] will burst" - Ebonyi, Nigeria, Endline Comparison FGD, Community Women.

"Women who are not married that are having affair with different men can have this fistula" - Katsina, Nigeria, Endline Intervention FGD, Community Men.
}

\section{COMMUNITY PERCEPTIONS AND PREFERENCES OF FISTULA CARE OPTIONS}

Topics related to traditional and cultural beliefs and practices emerged in the context of fistula care options and care seeking. Although nearly all the groups highlighted limitations of local remedies and herbs, traditional healers or "witch doctors" were described as being often sought out to treat or prevent various health problems, including fistula. Respondents from the Central Uganda groups men- tioned traditional medicine more readily than the community groups from Katsina or Ebonyi and there was a slight reduction at endline in the overall reporting of care seeking from traditional healers or local herbs for fistula treatment. One man from a Central Uganda endline comparison group explained that in their community, very few people initially seek treatment at hospitals; often they will go to the "witch doctor" and use local herbs which will only slightly improve the condition. In Central Uganda, baseline groups (men and women) described women with fistula seeking herbal treatment, but this did not emerge in endline comparison or intervention areas. Use of herbs and traditional healers were also described as contributing to delays in seeking medical attention and some of the women express that these local herbs can make the condition worse, rather than treat it. The men described women as being "easily duped" by traditional healers but they went on to clarify: "there is no local herb that heals fistula."

Participants in the Katsina groups also expressed a historical cultural preference for traditional healers among some in their communities, but respondents suggested that women will seek treatment from traditional healers due to a lack of money.

Respondents often cited lack of money as a primary reason for seeking traditional healers in the endline intervention periods and they concurred at all time points and sites that poverty was the most significant barrier to prevention and treatment of fistula; this barrier explored in detail elsewhere. ${ }^{23}$ Male and female respondents in Ebonyi described traditional medicine as a more-affordable alternative to hospital treatment). As observed in Ebonyi groups, endline comparison, and endline intervention Katsina women's groups described traditional treatments as being a way to save money and the perception that traditional medicine worked better than western. One endline intervention women's groups in Katsina emphasized that women continued to pursue traditional treatments for conditions like fistula, not due to a lack of money, but because "they believe that the traditional methods will work for them."

Awareness that fistula can be surgically repaired free of charge at fistula repair centers in each of the study regions varied. Individuals within discussion groups were more likely to know about the fistula centers and that fistula can be repaired with surgery if they personally knew someone (sister-in-law, neighbor, etc.) who had experienced fistula and been repaired at the fistula center. In addition, individuals who had heard radio or tv announcements were aware of the free repair services available in their region. In Katsina, we saw that awareness of the National Fistula Center at Babbar Ruga increased among men and women in the endline intervention groups compared to the baseline groups. The endline comparison groups in Katsina did not see as much increased awareness which is likely due to the reduced exposure to the project intervention.

\section{ATTITUDES TOWARD WOMEN LIVING WITH FISTULA}

\section{PERSISTENT STIGMA BUT INCREASED EMPATHY AND WILLINGNESS TO HELP WOMEN WITH FISTULA}

Communities perceived that women living with fistula feel 
immense shame due to their condition but variably described how shame manifests and influences women's behavior. Men and women in all study sites talked about women being afraid of stigmatization, hiding their condition from others and embarrassment at the odor from fistula. Stigma was thought to be caused by several factors: bad smell surrounding her and her home, abandonment by family, fear of judgement from others (i.e., "they will think I loved many men") and feeling that she is alone with fistula.

"If you have vaginal fistula, one cannot comfortably interact with people. Wherever you are you have to be isolated, feeling ashamed." - Katsina, Nigeria, Baseline, Community Women.

\section{"Her health challenge may disgrace her in the presence of people, it will be shameful, the person will say that it is better for her to stay at home." - Ebonyi, Nigeria, Endline Comparison, Community Men.

\begin{abstract}
"[Women with fistula] are stigmatized because of the smell. She has no say at home. In fact, she doesn't know what to do and even her family members do not know what to do for her, so she is left there helpless." - Central Uganda, Endline Intervention FGD, Community Women.
\end{abstract}

Stigma was commonly associated (by some men and women in all sites) with impeding women living with fistula from seeking medical attention. Interestingly, some participants in baseline and endline comparison women's groups in Central Uganda described the opposite effect; that shame and stigma surrounding the smell of their condition encourages care-seeking.

\section{"The way we are seated here, if I am a fistula patient a bad smell would be coming out of me and it would make me feel uncomfortable among people; it pushes me to get treatment" - Central Uganda, Endline Comparison FGD, Community Women.}

Although shame and stigma were perceived as being ubiquitous for women living with fistula in all study groups across time points, community attitudes toward these women showed an increase in empathy for these women following intervention implementation. The endline intervention group compared to baseline and endline comparison groups showed an enhanced desire or willingness to provide psychosocial support to women living with fistula. Prior to the intervention, only Central Uganda men expressed - from a practical, non-emotive standpoint - the idea that if his wife has fistula, a husband should help facilitate her access to care. The endline comparison groups in Ebonyi and the women from Central Uganda discussed supporting women with fistula beyond logistics and entering into the realm of psychosocial support; they encouraged women not to feel ashamed of their sickness and promote the idea that women with this condition could still be active members of their communities and that communities should not fear them. Although endline comparison groups were not directly exposed to the community- or PHC-based health messaging included in the intervention, they may have been within range of radio messaging. In endline intervention groups, this emotively emergent community support was more apparent. All three men's groups spoke about how these women should not feel ashamed of their condition and describe how men can be more "proactive" by advising women and spreading awareness. The women's groups in Katsina and Central Uganda most clearly demonstrated the presence of empathy among community women for women living with fistula by offering consolation, overcoming the sense of loneliness, and a non-blame attitude.

"Any person that is suffering fistula should not be ashamed, she should hurry and go to those that will treat her, she should forget about money, she should inform you people and she will be treated free." - Ebonyi, Endline Intervention FGD, Community Men.

"I [would] console her and give her advice and also encourage her to put shame aside and [tell] her she's not the first, $[. .$.$] there are very many other people with the same$ situation. [...] So, I tell her to be strong and go to the hospital so that she can [be] cured." - Central Uganda, Endline Intervention FGD, Community Women.

\section{VARIED EXPOSURE TO AND AWARENESS OF INTERVENTION COMPONENTS}

Community-level exposure to the barrier reduction intervention was evident to varying degrees in Ebonyi, Katsina, and Central Uganda. Unsurprisingly, endline intervention groups seemed to have the most exposure and awareness of various intervention components. Radio was a commonlymentioned source of information about fistula, its treatability, the existence of a hotline, the availability of free repair services and how to get a voucher for free transportation to the treatment facility. Posters at health centers and in communities were also mentioned as sources of knowledge about the fistula hotline. Groups mention that this information was also shared through community health agents and health providers. Several groups described ways in which knowledge of fistula, the hotline, treatment, and the transportation voucher spread within their communities beyond the strategies used by the intervention. Word-of-mouth, $\mathrm{TV}$, and social media are common additional channels for information to organically spread.

"I have never seen this number, but I have heard that a number exists. My wife went to visit her friend and she was given a number that she could share with other women, so they could call to seek information and also where to get treatment in case this form of illness is to ever arise around them." - Katsina, Nigeria, Endline Intervention FGD, Community Men.

"When a person deep in the village gets that voucher, she will get free transportation and goes to be treated. Now that influences her to make a decision to go." - Central Uganda, Uganda, Endline Intervention FGD, Community Men.

"[Our community health agent] said that if we see anybody that is suffering [from fistula], we should bring the person to him so that he can call the driver of the vehicle to come and take the person to the hospital, even if the person does not have phone, that he will use his phone to call them." Ebonyi, Nigeria, Endline Intervention FGD, Community Women. 
To some extent, women's knowledge of the intervention was higher than men; though overall, all endline intervention groups showed mixed awareness of the hotline and the availability of vouchers.

Most community members in the endline comparison groups were not aware of the transportation voucher, the fistula hotline and did not report learning about fistula or these interventions from their community health agents. The few individuals in the endline comparison groups who expressed awareness of either the transportation voucher or the hotline, had learned about them from radio messaging or from posters but did not seem to understand these components fully.

\section{DISCUSSION}

This study demonstrated that implementing a multi-component intervention can lead to incremental improvements in community knowledge of fistula causes, signs and treatment options, as well as in expressed empathy toward women living with fistula. Exploration of knowledge and attitudes toward fistula across a diversity of men and women's perspectives in three distinct sociocultural and geographic settings have general implications for SBC programming. While few differences exist across settings, overall patterns of shifting community perspectives demonstrate the need to reduce misinformation, as a step toward fistula-related stigma reduction.

\section{CHANGES IN INTERVENTION AREAS}

Exposure to a multi-component intervention incorporating SBC strategies can advance the slow process of changing community-wide perceptions of stigmatized conditions like fistula. This intervention aimed to improve community knowledge of fistula and attitudes toward women living with it; our study found modest improvements in both. The most consistently-expressed attitude stated by community members about women living with fistula is their tendency to be isolated (by choice or not) from families and communities and their decision to seek care is affected by their mental state and sense of self-worth that stems from the condition's associated-shame and stigma. Our finding is consistent with similar research in other settings. ${ }^{15,24} \mathrm{Al}$ though shame continues to deeply affect women living with fistula, the notable shifts in community members' attitudes toward supporting these women and mitigating shame, following exposure to the SBC intervention, are promising. Prevailing opinions highlight the need for community members to provide instrumental and psychosocial support to women living with fistula, including the encouragement and information to help them seek treatment.

\section{DIFFERENCES AMONG MEN AND WOMEN}

Knowledge and awareness of fistula causes, symptoms, and treatment options did not vary widely between men and women respondents, though women tended to have slightly more correct information on these topics compared to men and men were more likely to incorrectly associate fistula with female sexuality. An exception to this trend is that men generally were more likely than women to talk about early marriage and early pregnancy as causing fistula; this cause was also more prominently mentioned in Katsina and Central Uganda where early marriage for girls and young women is more common. ${ }^{25,26}$ The tendency of women demonstrating more correct information may be attributed to the linkages between women with fistula, the community agents, health facility workers who provide ANC and counselling within the intervention.

\section{TRADITIONAL CARE}

Cultural beliefs and use of traditional or alternative medicine were described as playing a role in causes of and treatment for fistula by all respondent groups - suggesting the need for continuous SBC interventions in both Nigeria and Uganda - however the details of these practices varied. Poverty and the perceived cost of medical treatment for fistula lead women to seek traditional alternatives, ultimately causing a delay in the reparative care. Tradition or culture are not perceived as barriers to seeking medical care for fistula, but rather traditional medicine serves as an affordable alternative to hospital-based care; poverty is the predominant barrier for seeking fistula treatment. ${ }^{23}$ Our study showed, across all sites, the belief that fistula can be caused by witchcraft or evil spirits was less prominent compared to prior regional work in Nigeria, Uganda, Ethiopia and Malawi.6,7,14,27 Future programming should strive to identify which cultural beliefs are prominent in a particular setting and tailor the health messaging accordingly.

\section{PROGRAMMING IMPLICATIONS}

Through this study, we underscore the importance of understanding community perspectives and intervening at community level with interventions aimed at increasing community awareness and understanding as a means of mitigating stigma. While community perceptions indicate an expectation that women living with fistula feel stigmatized, the normative attitudes towards women with fistula were far more supportive than stigmatizing. Men and women are increasingly aware of and open to supporting women living with fistula. Though community-based strategies have been explored in addressing other stigmatized conditions, ${ }^{28,29}$ we recommend further exploration of these approaches for fistula. Future efforts should aim to build on this positive trend in community norms around stigma to ultimately improve care-seeking and access to reparative services and improve wellbeing of those who have experienced fistula. Exposure to the community-integrated intervention in Ebonyi, Katsina and Central Uganda provides one example of such a strategy. However, due to the nature and reach of mass media, there was likely some cross-contamination into the endline comparison sites in our study. The intervention aimed to spread awareness and increase knowledge of fistula, its symptoms, its causes, as well as where and how to seek treatment by employing multiple routes of communication - community-based agents, PHC providers and mass media. In designing the intervention, we had posited that any single one of these communication channels is inadequate to increase community 
knowledge and awareness when implemented separately. This intervention was designed to use all three together to maximize the saturation of community knowledge of fistula, treatment options and the transportation voucher to improve women's access to reparative services. From the results of the FGDs with community members, we learned that community members tended to cite one to two of the three communication channels as being a source of their knowledge on fistula. Radio and community agents (specifically Village Health Team members in Central Uganda) were the most commonly recognized aspect of the overall intervention. These findings support the notion that no single communication channel is sufficient to improve community knowledge on its own.

\section{LIMITATIONS}

Limitations of this study fact include that we were unable to ensure a true control group due to cross-contamination from radio messaging. Additionally, as a nested study, the primary target population for the intervention was women living with fistula rather than the communities they live in. Furthermore, its direct intervention effects cannot be claimed given the complexity of the SBC intervention, the difficulty of measuring normative perspectives, and the slow process required to meaningfully shift community attitudes over time. These findings could also be subject to social acceptability bias, or when respondents are hesitant to admit to a stigmatizing attitude (toward women with fistula) if they feel it would reflect negatively on them. In order to minimize this as much as possible, the local study team was familiar with and trained in now to navigate cultural norms in each setting. Future studies assessing community attitudes and norms should consider longer study periods that will allow for longitudinal qualitative approaches that follow up with intervention exposure over multiple points in time.

\section{CONCLUSIONS}

SBC happens slowly at community level; it relies on gradual, sustainable cultural and behavioral modifications toward the desired outcome. This multi-component intervention contributed to increases in community empathy, compassion, and willingness to help women living with fistula. This-coupled with reduction in misinformation regarding fistula, its cause and how to access treatment-is an important intermediate point in the path toward comprehensive community understanding of fistula and stigma reduction.

\section{ACKNOWLEDGEMENTS}

The authors acknowledge the study participants for sharing their views. We thank Charles Nwaigwe (Population Council-Nigeria) and Hassan Kanakulya (EngenderHealthUganda) who were instrumental in the implementing and managing data collection. We also acknowledge Erin Mielke and Mary Ellen Stanton at USAID, Vandana Tripathi at EngenderHealth for their review of this manuscript.

\section{FUNDING}

This work was funded by the United States Agency for International Development (USAID) under associate cooperative agreement AID-OAA-A14-00013. The opinions expressed are those of the authors and do not necessarily reflect the views of USAID, or the United States Government.

\section{AUTHORSHIP CONTRIBUTIONS}

KK conducted qualitative data analysis and wrote the manuscript. PS conceptualized, guided, and contributed to writing the manuscript. Implementation Research (parent) study design was done by CW and PS. CN, EN, and GO oversaw and managed data collection, as well as contributed to preliminary analyses. All authors reviewed and approved the final manuscript.

\section{COMPETING INTERESTS}

The authors completed the Unified Competing Interest form at www.icmje.org/coi_disclosure.pdf (available upon request from the corresponding author), and declare no conflicts of interest.

\section{CORRESPONDENCE TO:}

\author{
Karen Kirk, MPH \\ Staff Associate \\ Population Council \\ One Dag Hammarskjold Plaza \\ New York, NY, 10017, USA.
}

Submitted: February 05, 2021 GMT, Accepted: April 04, 2021 GMT 


\section{REFERENCES}

1. Adler AJ, Ronsmans C, Calvert C, Filippi V. Estimating the prevalence of obstetric fistula: A systematic review and meta-analysis. BMC Pregnancy Childbirth. 2013;13(1):1-14. doi:10.1186/1471-2393-1 $\underline{3-246}$

2. Mallick L, Tripathi V. The association between female genital fistula symptoms and gender-based violence: A multicountry secondary analysis of household survey data. Trop Med Int Heal. 2018;23(1):106-119. doi:10.1111/tmi.13008

3. Tripathi V, Arnoff E, Sripad P. Removing barriers to fistula care: Applying appreciative inquiry to improve access to screening and treatment in Nigeria and Uganda. Health Care Women Int. 2020;41(5):584-599. doi:10.1080/07399332.2019.1638924

4. Baker Z, Bellows B, Bach R, Warren C. Barriers to obstetric fistula treatment in low-income countries: a systematic review. Trop Med Int Heal. 2017;22(8):938-959. doi:10.1111/tmi.12893

5. Banke-Thomas AO, Kouraogo SF, Siribie AA, Taddese HB, Mueller JE. Knowledge of obstetric fistula prevention amongst young women in urban and rural Burkina Faso: A cross-sectional study. PLoS One. 2013;8(12):1-8. doi:10.1371/journal.pone.00859 $\underline{21}$

6. Kasamba N, Kaye DK, Mbalinda SN. Community awareness about risk factors, presentation and prevention and obstetric fistula in Nabitovu village, Iganga district, Uganda. BMC Pregnancy Childbirth. 2013;13. doi:10.1186/1471-2393-13-229

7. Changole J, Kafulafula U, Sundby J, Thorsen V. Community perceptions of obstetric fistula in Malawi. Cult Health Sex. 2019;21(5):605-617. doi:10.1080/1369 $\underline{1058.2018 .1497813}$

8. Kazaura MR, Kamazima RS, Mangi EJ. Perceived causes of obstetric fistulae from rural southern Tanzania. Afr Health Sci. 2011;11(3):377-382.

9. Lufumpa E, Doos L, Lindenmeyer A. Barriers and facilitators to preventive interventions for the development of obstetric fistulas among women in sub-Saharan Africa: A systematic review. BMC Pregnancy Childbirth. 2018;18(1):1-9. doi:10.1186/s12 884-018-1787-0

10. Wegner MN, Ruminjo J, Sinclair E, Pesso L, Mehta M. Improving community knowledge of obstetric fistula prevention and treatment. Int J Gynecol Obstet. 2007;99(SUPPL. 1):108-111. doi:10.1016/j.ijgo.2007.0 $\underline{6.030}$
11. Seim AR, Alassoum Z, Bronzan RN, Mainassara AA, Jacobsen JL, Gali YA. Pilot communitymobilization program reduces maternal and perinatal mortality and prevents obstetric fistula in Niger. Int J Gynecol Obstet. 2014;127(3):269-274. doi:10.1016/j.ijg $\underline{0.2014 .06 .016}$

12. Yeakey MP, Chipeta E, Taulo F, Tsui AO. The lived experience of Malawian women with obstetric fistula. Cult Heal Sex. 2009;11(5):499-513. doi:10.1080/13691 050902874777

13. Lyimo MA, Mosha IH. Reasons for delay in seeking treatment among women with obstetric fistula in Tanzania: A qualitative study. BMC Womens Health. 2019;19(1):1-8. doi:10.1186/s12905-019-0799-x

14. Emma-Echiegu N, Okoye UO, Odey ES. Knowledge of causes of VVF and discrimination suffered by patients in Ebonyi State, Nigeria: a qualitative study. Soc Work Public Health. 2014;29(5):417-427. doi:10.10 80/19371918.2013.853635

15. Changole J, Thorsen VC, Kafulafula U. "I am a person but I am not a person”: Experiences of women living with obstetric fistula in the central region of Malawi. BMC Pregnancy Childbirth. 2017;17(1):1-13. ㄸ oi:10.1186/s12884-017-1604-1

16. Lavender T, Wakasiaka S, McGowan L, Moraa M, Omari J, Khisa W. Secrecy inhibits support: A grounded theory of community perspectives of women suffering from obstetric fistula, in Kenya. Midwifery. 2016;42(September):54-60. doi:10.1016/ j.midw.2016.10.001

17. Roush KM. Social implications of obstetric fistula: an integrative review. J Midwifery Womens Health. 2009;54(2):e21-33. doi:10.1016/i.jmwh.2008.09.005

18. O.Nyumba T, Wilson K, Derrick CJ, Mukherjee N. The use of focus group discussion methodology: Insights from two decades of application in conservation. Methods Ecol Evol. 2018;9(1):20-32. do $\mathrm{i}: 10.1111 / 2041-210 \mathrm{X} .12860$

19. Tripathi V, Arnoff E, Sripad P. Removing barriers to fistula care: Applying appreciative inquiry to improve access to screening and treatment in Nigeria and Uganda. Health Care Women Int. 2020;41(5):584-599. doi:10.1080/07399332.2019.1638 $\underline{924}$ 
20. Population Council. Reducing Barriers to Accessing Fistula Repair in Nigeria and Uganda: An Implementation Research Study.; 2020. https://knowle dgecommons.popcouncil.org/cgi/viewcontent.cgi?arti cle $=2431 \&$ context $=$ departments_sbsr-rh

21. Hennink MM, Kaiser BN, Weber MB. What Influences Saturation? Estimating Sample Sizes in Focus Group Research. Qual Heal Res. 2019;29(10):1483-1496.

22. Ngongo CJ, Raassen TJIP, Lombard L, van Roosmalen J, Weyers S, Temmerman M. Delivery mode for prolonged, obstructed labour resulting in obstetric fistula: a retrospective review of 4396 women in East and Central Africa. BJOG An Int J Obstet Gynaecol. 2020;127(6):702-707. doi:10.1111/14 71-0528.16047

23. Keya KT, Sripad P, Nwala E, Warren CE. "Poverty is the big thing": exploring financial, transportation, and opportunity costs associated with fistula management and repair in Nigeria and Uganda. Int J Equity Health. 2018;17(1):70. doi:10.1186/s12939-01 8-0777-1

24. Bashah DT, Worku AG, Yitayal M, Azale T. The loss of dignity: Social experience and coping of women with obstetric fistula, in Northwest Ethiopia. BMC Womens Health. 2019;19(1):1-10. doi:10.1186/s 1 2905-019-0781-7
25. Uganda Bureau of Statistics. GOVERNMENT OF UGANDA Uganda Demographic and Health Survey 2016. Udhs 2016. Published online 2016:625. http s://www.dhsprogram.com/

26. National Population Commission (NPC) [Nigeria], ICF. Nigeria Demographic Health Survey 2018. DHS Progr ICF Rockville, Maryland, USA. Published online 2019:748. https://dhsprogram.com/publications/publi cation-fr359-dhs-final-reports.cfm

27. Muleta M, Hamlin EC, Fantahun M, Kennedy RC, Tafesse B. Health and social problems encountered by treated and untreated obstetric fistula patients in rural Ethiopia. J Obstet Gynaecol Canada JOGC = J d'obstetrique Gynecol du Canada JOGC. 2008;30(1):44-50. doi:10.1016/S1701-2163(16)3271 $\underline{2-8}$

28. Figueroa ME, Poppe P, Carrasco M, et al. Effectiveness of Community Dialogue in Changing Gender and Sexual Norms for HIV Prevention: Evaluation of the Tchova Tchova Program in Mozambique. J Health Commun. 2016;21(5):554-563. doi:10.1080/10810730.2015.1114050

29. French H, Greeff M, Watson MJ. Experiences of people living with HIV and people living close to them of a comprehensive HIV stigma reduction community intervention in an urban and a rural setting. Sahara J. 2014;11(1):105-115. doi:10.1080/17 290376.2014.938104 